(2) Open Access Full Text Article

\title{
Impact of Antecedent Aspirin Use on Infarct Size, Bleeding and Composite Endpoint in Patients with de Novo Acute Myocardial Infarction
}

\section{Asim Enhos \\ Erdem Karacop}

Bezmialem Foundation University, Faculty of Medicine, Department of Cardiology, Istanbul, Turkey
Correspondence: Erdem Karacop Bezmialem Foundation University, Faculty of Medicine, Department of Cardiology, Adnan Menderes Avenue, Vatan Street, Fatih, 34093, Istanbul, Turkey

Tel $+90212453 \quad 1700$

Fax +90 212 621 7580

Email erdemkaracop@hotmail.com
Background: The study aimed to evaluate the impact of antecedent aspirin use on infarct size, bleeding and composite endpoint in patients with de novo acute myocardial infarction. Patients and Methods: A total of 562 consecutive patients with de novo acute myocardial infarction were included in this prospective cohort study. Patients were assigned into two groups based on presence $(n=212)$ and absence $(n=350)$ of prior aspirin use. Primary endpoint was myocardial infarct size, as estimated by troponin I peak. In-hospital mortality, bleeding and composite clinical endpoint including cardiogenic shock, stroke, in-hospital mortality and major bleeding were also evaluated.

Results: Although GRACE and CRUSADE scores were higher, troponin I peak was lower in prior aspirin users. This result was maintained after adjustment for baseline ischemic risk profile and other major confounders including MI type and location. Despite high CRUSADE score, there was no increase in major and minor bleeding. Minimal bleeding was higher in antecedent aspirin users. When it was adjusted for the CRUSADE score, a similar risk was reported.

Conclusion: Patients with de novo acute myocardial infarction using aspirin for primary prevention have an unexpectedly smaller infarct size and similar bleeding rates.

Keywords: acute myocardial infarction, aspirin, infarct size, primary prevention

\section{Introduction}

Aspirin has proven evidence of benefit and is guideline recommended as a treatment option for secondary prevention of cardiovascular events. ${ }^{1}$ However, a promising decrease in adverse cardiovascular events was offset by an increase in bleeding complications for primary prevention. ${ }^{1}$ The occurrence of an arterial thrombotic event despite aspirin therapy is defined as aspirin resistance. Possible mechanisms are incomplete suppression of thromboxane A2 generation, stress-induced cyclooxygenase-2 expression in platelets and increased platelet sensitivity to adenosine diphosphate and collagen. Twenty years ago, the main explanation for patients who had an acute coronary syndrome despite antecedent aspirin therapy was 'aspirin resistance'.2 Contemporary use of aspirin for secondary prevention of atherosclerotic cardiovascular disease (ASCVD) has been widely accepted, as the benefits linked to the reduction of clinical events outweigh the risk of major bleeding. However, the potential of aspirin to reduce atherothrombotic events, its overall efficacy 
and safety in primary ASCVD prevention remains unclear, despite being used for this purpose for decades. $^{3}$

Current myocardial infarction (MI) therapy has evolved from the conservative approach to early invasive strategies and the combination of more potent antiplatelet and statin therapy. ${ }^{4} \mathrm{MI}$ event rates and in-hospital case fatalities declined in 1985-2010 in almost all populations analysed due to the rapidly expanding number of hospitals that were capable of performing percutaneous coronary interventions (PCIs). ${ }^{5}$ However, the increased incidence of obesity and diabetes in the overall population has resulted in a modest increase in morbidity. Prior aspirin use has recently been shown to decrease serious vascular events, including MI and stroke, in diabetics without cardiovascular disease. ${ }^{6}$ Additionally, aspirin pretreatment has been associated with similar primary endpoints, including death, MI and stroke, in patients at moderate cardiovascular risk. $^{7}$

Bleeding risk with aspirin prescribed for primary prevention should be taken into consideration while interpreting these results. Very low dose aspirin $(<100 \mathrm{mg})$ was found to be related to increased major gastrointestinal bleeding. ${ }^{8}$ Hence, the findings of A Study of Cardiovascular Events in Diabetes (ASCEND) demonstrated a $12 \%$ reduction in the incidence of major adverse cardiac events in diabetic patients; however, this was outweighed by a $29 \%$ increase in the risk of major bleeding complications. ${ }^{6}$ The Aspirin to Reduce Risk of Initial Vascular Events (ARRIVE) trial has consistently verified this complication. ${ }^{7}$

Possible explanations for increased bleeding might be that chronic aspirin users usually have established $\mathrm{ASCVD}^{9}$ and are generally older. ${ }^{9}$ The recommendation for aspirin use as primary prevention has been downgraded over the years. Recent guidelines restricted the use of aspirin to 40-70 year-old-adults who are at higher risk of cardiovascular events. ${ }^{10}$ It should not be used among adults older than 70 or any person who is at increased risk of bleeding. ${ }^{10}$

A decrease in nonfatal infarction in chronic aspirin users has been demonstrated recently. ${ }^{6}$ It was put forward that this decrease could translate into a reduction in fatal MI with randomized trials with long-term follow-up.

One of the most consequential determinants of outcome in MI is infarct size, which is important for therapeutic interventions. ${ }^{11}$ Cardiac troponins (Tn) provide quantitative estimations of infarct size. ${ }^{12}$ Omura et al reported a close relationship between TnT and infarct size in acute MI. ${ }^{13}$ The trends for TnT and TnI assays were remarkably similar in the same population. ${ }^{14}$ Measurements of Tn, including area under curve (AUC) and peak, have consistently verified that the correlations between $\mathrm{Tn}$ and different imaging modalities of infarct size are 0.6 and $0.75 .{ }^{14}$ Single-point measures and 24 hour onwards were found to be equally effective. ${ }^{15}$ Although aspirin therapy is a cornerstone in the treatment of MI and reduces mortality and hospitalization after ischemic attack, ${ }^{16}$ there are not enough investigations about effects of aspirin pretreatment on infarct size. $\mathrm{Wu}$ et al postulated in his 2002 study that acute infarct size was a stronger predictor of cardiac death, nonfatal reinfarction and symptomatic heart failure than ejection fraction and end-systolic volume index. ${ }^{17}$ In the contemporary era, we tried to investigate the role of aspirin pretreatment for primary prevention prior to $\mathrm{MI}$ in a PCI-capable tertiary center. This center could perform primary PCI systematically on a $24 / 7$ basis for all patients.

The Global Registry of Acute Coronary Events (GRACE) and the Can Rapid risk stratification of Unstable angina patients Suppress ADverse outcomes with Early implementation of the American College of Cardiology/American Heart Association guidelines (CRUSADE) scores are among the most frequently used risk assessment tools. ${ }^{18,19}$ GRACE was primarily developed to predict in-hospital mortality in patients with both ST-segment elevation myocardial infarction (STEMI) and non-ST-segment elevation myocardial infarction (NSTEMI). CRUSADE was developed from a cohort of NSTEMI patients, with a primary focus on bleeding. Both scores are currently used in broad acute coronary syndrome populations to assess the risk of both mortality and bleeding. In concordance with previous studies, GRACE scores were used to assess clinical risk and CRUSADE scores to assess bleeding risk in this study.

Cardiovascular disease prevention is defined as a combination of actions aimed at minimizing or eliminating the deleterious effect of cardiovascular disease at individual or population level. Modification of lifestyle is the primary focus of interventions. Moreover, lipid-lowering with statins ${ }^{20,21}$ and antihypertensive therapy in conjunction with this primary focus are considered as two components of prevention if targeted at individuals at high risk. ${ }^{22}$ Antiplatelet therapy including aspirin is not recommended in individuals without cardiovascular disease. ${ }^{23}$ In this study, we investigated the effect of aspirin use for primary 
prevention prior to MI on myocardial infarct size, which was evaluated by TnI peak value and in-hospital bleeding.

\section{Patients and Methods Study Patients}

This prospective, single-center study was conducted at Bezmialem University between September 10, 2018 and March 8, 2020; 562 patients with de novo MI (both STEMI and NSTEMI) were enrolled. Patients were assigned into two groups based on presence $(n=212)$ and absence $(n=350)$ of prior aspirin use.

Inclusion criteria were: (1) age $>18$ years; (2) duration of pain onset to hospital admission of 72 hours; ${ }^{24}$ (3) MI denotes acute myocardial injury with clinical evidence of acute myocardial ischemia and with detection of a rise and/or fall of cTn values with at least one value above the 99th percentile upper range limit and at least one of the following: (a) symptoms of myocardial ischemia; (b) new ischemic electrocardiographic changes; (c) development of pathological Q waves ${ }^{25}$ and (4) pretreatment with aspirin at least 30 days before admission.

Exclusion criteria were: (1) history of previous MI; (2) pretreatment with antiplatelets other than aspirin, such as clopidogrel, prasugrel or others; and (3) severe physical disability or inability to comprehend the study.

Study was approved by Bezmialem University Ethics Committee (number 71306642) on May 21, 2018 and the study was conducted in accordance with ethical principles described by the Declaration of Helsinki. All participants signed written informed consent forms before study enrollment.

\section{Study Design}

Case report forms which included compliance and duration of antecedent aspirin use were given to each patient. A minimum duration of 30 days until index event was accepted as antecedent aspirin use.

Demographic details, clinical characteristics and laboratory findings were recorded, respectively. Measurement of TnI (Beckman Coulter, Fullerton, California, USA) was repeated at serial time intervals until 24 hours after reaching the peak value. Cardiac Tn provides quantitative estimation of infarct size. ${ }^{12}$ Admission Tn values are also predictive of future risk, but their correlation with infarct size is poor. ${ }^{14}$ The trends for $\mathrm{TnT}$ and $\mathrm{TnI}$ assays were remarkably similar in the same population. ${ }^{14}$ Measurements of Tn, including area under curve (AUC) and peak, have consistently verified that the correlations between $\mathrm{Tn}$ and different imaging modalities of infarct size are 0.6 and $0.75 .^{14}$ Single-point measures and 24 hour onwards were found to be equally effective. ${ }^{15}$ Echocardiography was performed within 24 hours of hospital admission. Ejection fraction was calculated using a modified Simpson's method.

GRACE score was used to assess clinical risk and improved the selection of patients for clinical and interventional procedures following an acute coronary event. ${ }^{18}$ CRUSADE score was used to determine bleeding risk. ${ }^{19}$ GRACE and CRUSADE scores were applied to both STEMI and NSTEMI patients.

The Thrombolysis In Myocardial Infarction (TIMI) bleeding classification of major, minor and minimal was applied to in-hospital adverse events. Our intention in using the TIMI bleeding classification was only to describe bleeding complications in detail, not to assess bleeding risk or ischemic risk. It concluded that major bleeding was an intracranial hemorrhage or $\mathrm{a} \geq 5 \mathrm{~g} / \mathrm{dl}$ decrease in hemoglobin concentration or $\mathrm{a} \geq 15 \%$ absolute decrease in hematocrit. ${ }^{26}$ Minor bleeding was described as a $\geq 3 \mathrm{~g} / \mathrm{dl}$ decrease in hemoglobin concentration or $\mathrm{a} \geq 10 \%$ absolute decrease in hematocrit. ${ }^{26}$ Minimal bleeding was described as a $<3 \mathrm{~g} / \mathrm{dl}$ decrease in hemoglobin concentration or a $<$ $10 \%$ decrease in hematocrit. ${ }^{27}$

TIMI flow grade before and after PCI was evaluated using a standard method. ${ }^{28}$ Current guidelines were taken into consideration while giving optimal medical treatment and providing coronary revascularization for all patients. $^{4,24}$

Infarct size was the primary endpoint of the study. It was estimated by TnI peak value. STEMI and NSTEMI subcategorizations were performed for infarct size (Tables 1 and 2). Additionally, the secondary endpoint was in-hospital bleeding. STEMI and NSTEMI subcategorizations were also performed for bleeding (Tables 3 and 4). Stroke was defined as a new neurological deficit of more than 24 hours duration. Cardiogenic shock, stroke, in-hospital mortality and major bleeding were considered as a composite endpoint.

\section{Statistical Analysis}

A sample size of 504 patients was calculated under the assumption of a $5 \mathrm{ng} / \mathrm{mL}$ difference in mean TnI peak value between two groups. This sample size allowed an $80 \%$ statistical power to be deemed significant ( $\alpha$ error of 0.05 ). 
Table I Multiple Linear Regression Analysis for Infarct Size in STEMI Subgroups

\begin{tabular}{|c|c|c|c|c|}
\hline & \multicolumn{4}{|l|}{ Infarct Size } \\
\hline & $\begin{array}{l}\text { BETA (Non-standard } \\
\text { Coefficient) }\end{array}$ & $\begin{array}{l}95 \% \mathrm{Cl} \text { for } \\
\text { BETA }\end{array}$ & $\begin{array}{l}\text { BETA (Standard } \\
\text { Coefficient) }\end{array}$ & p-value \\
\hline Prior aspirin treatment & 14.752 & $10.927-18.578$ & 0.335 & $<0.001$ \\
\hline GRACE score & 0.266 & $0.175-0.356$ & 0.288 & $<0.001$ \\
\hline $\begin{array}{l}\text { AMI location (anterior vs } \\
\text { nonanterior) }\end{array}$ & 20.611 & $16.533-24.710$ & 0.477 & $<0.001$ \\
\hline Smoking status & 6.030 & $2.034-10.026$ & 0.133 & 0.003 \\
\hline Prior beta-blocker treatment & 2.669 & $-4.583-9.920$ & 0.032 & 0.469 \\
\hline Prior statin treatment & 1.892 & $-2.449-6.233$ & 0.038 & 0.391 \\
\hline
\end{tabular}

Abbreviations: AMI, acute myocardial infarction; GRACE, Global Registry of Acute Coronary Events; STEMI, ST-elevation myocardial infarction.

Table 2 Multiple Linear Regression Analysis for Infarct Size in NSTEMI Subgroups

\begin{tabular}{|c|c|c|c|c|}
\hline & \multicolumn{4}{|l|}{ Infarct Size } \\
\hline & $\begin{array}{l}\text { BETA (Non-standard } \\
\text { Coefficient) }\end{array}$ & $\begin{array}{l}95 \% \mathrm{Cl} \text { for } \\
\text { BETA }\end{array}$ & $\begin{array}{l}\text { BETA (Standard } \\
\text { Coefficient) }\end{array}$ & p-value \\
\hline Prior aspirin treatment & 2.593 & $1.470-3.716$ & 0.250 & $<0.001$ \\
\hline GRACE score & 0.007 & $-0.030-0.045$ & 0.022 & 0.695 \\
\hline $\begin{array}{l}\text { AMI location (anterior vs } \\
\text { nonanterior) }\end{array}$ & -0.074 & $-1.306-1.158$ & -0.007 & 0.906 \\
\hline Smoking status & 2.859 & $1.366-4.351$ & 0.212 & $<0.001$ \\
\hline Prior beta-blocker treatment & 0.221 & $-2.213-2.655$ & 0.010 & 0.858 \\
\hline Prior statin treatment & 1.687 & $0.34 \mid-3.033$ & 0.136 & 0.014 \\
\hline
\end{tabular}

Abbreviations: AMI, acute myocardial infarction; GRACE, Global Registry of Acute Coronary Events; NSTEMI, non-ST-elevation myocardial infarction.

Table 3 Univariate and Multivariate Logistic Regression Analysis for Bleeding in STEMI Subgroup

\begin{tabular}{|c|c|c|c|c|}
\hline \multirow[t]{2}{*}{ Variables } & \multicolumn{2}{|l|}{ Univariate Analysis } & \multicolumn{2}{|l|}{ Multivariate Analysis } \\
\hline & Odds Ratio (95\% Cl) & p-value & Odds Ratio (95\% Cl) & p-value \\
\hline Prior aspirin treatmen & $1.962(0.949-4.055)$ & 0.066 & & \\
\hline Age & $1.010(0.97 I-I .05 I)$ & 0.608 & & \\
\hline Hypertension & $1.376(0.627-3.020)$ & 0.436 & & \\
\hline CRUSADE score & I.II5 (I.072-I.I58) & $<0.001$ & $1.113(1.07 \mid-1.158)$ & $<0.001$ \\
\hline Clopidogrel treatment & $1.372(0.64 I-2.936)$ & 0.406 & & \\
\hline Ticagrelor treatment & $1.348(0.570-3.187)$ & 0.496 & & \\
\hline Glycoprotein IIB/IIIA inhibitor treatment & $2.879(1.309-6.333)$ & 0.009 & $2.984(1.204-7.400)$ & 0.018 \\
\hline
\end{tabular}

Abbreviations: CRUSADE, Can Rapid risk stratification of Unstable angina patients Suppress ADverse outcomes with Early implementation of the American College of Cardiology/American Heart Association guidelines; STEMI, ST-elevation myocardial infarction. 
Table 4 Univariate and Multivariate Logistic Regression Analysis for Bleeding in NSTEMI Subgroup

\begin{tabular}{|l|l|l|l|l|}
\hline \multirow{2}{*}{ Variables } & \multicolumn{2}{|l|}{ Univariate Analysis } & \multicolumn{2}{l|}{ Multivariate Analysis } \\
\cline { 2 - 5 } & Odds Ratio (95\% Cl) & p-value & Odds Ratio (95\% Cl) & p-value \\
\hline Prior aspirin treatment & $1.475(0.677-3.210)$ & 0.328 & & \\
\hline Age & $0.999(0.950-1.050)$ & 0.958 & & 0.673 \\
\hline Hypertension & $0.368(0.161-0.843)$ & 0.018 & $1.228(0.473-3.187)$ & $<0.001$ \\
\hline CRUSADE score & $1.156(1.102-1.212)$ & $<0.001$ & $1.149(1.094-1.207)$ & $0.169(0.041-0.690)$ \\
\hline Clopidogrel treatment & $5.529(1.869-16.356)$ & 0.002 & 0.013 \\
\hline
\end{tabular}

Abbreviations: CRUSADE, Can Rapid risk stratification of Unstable angina patients Suppress ADverse outcomes with Early implementation of the American College of Cardiology/American Heart Association guidelines; NSTEMI, non-ST-elevation myocardial infarction.

Data analysis was performed using SPSS 17 software (SPSS Inc., Chicago, Illinois, USA). The Shapiro-Wilk test was used for assessing whether or not the variables follow normal distributiont. Continuous variables were expressed as mean \pm standard deviation (SD). Variables with a skewed distribution were presented as median and interquartile range (IQR). Categorical variables were expressed as number and percentage. Differences between independent groups were assessed by unpaired Student's $t$-test for quantitative variables with normal distribution and Mann-Whitney's $U$-test for quantitative variables without normal distribution. Chi-square tests and Fisher's exact tests were performed for qualitative variables. Pearson's correlation analysis was performed for correlation between TnI peak value and GRACE score.

To identify variables that were associated with infarct size, a linear regression analysis was performed. TnI peak value was the dependent variable and GRACE score, type of myocardial infarction, smoking, antecedent medications, acute total occlusion and culprit vessel were integrated into analysis as independent variables. Additionally, linear regression analysis was repeated with the same variables for STEMI and NSTEMI subgroups for detailed analysis.

Moreover, univariate and multivariate logistic regression analyses were conducted to determine independent predictors of bleeding. Univariate analyses were performed for prior aspirin treatment, age, hypertension, CRUSADE score and intraprocedural medications including clopidogrel, ticagrelor and glycoprotein IIB/IIIA inhibitors. Variables found to be significant in univariate analysis were integrated into multivariate analysis. Logistic regression analyses were repeated for STEMI and NSTEMI subgroups for detailed analysis of bleeding.
To determine the independent predictive role of prior aspirin use for minimal, minor and major bleeding, univariate logistic regression analyses were conducted. The results were adjusted according to CRUSADE score. A p-value of $<0.05$ was considered statistically significant. All p-values were two-sided.

\section{Results}

The study population consisted of 562 consecutive patients with a mean age of $69.1 \pm 9.0$ years. Patients with NSTEMI $(n=302)$ and STEMI $(n=260)$ were included in this prospective cohort. Data for prior aspirin use was available for all patients; 212 (37.7\%) patients were taking aspirin at least 30 days before admission. Among these, 78 patients $(36.7 \%)$ were taking aspirin prescribed by a clinician and 134 patients (63.3\%) were taking aspirin bought over the counter.

Baseline demographic characteristics of the study group are presented in Table 5. Although age, gender, hypertension, hyperlipidemia, diabetes mellitus, coronary artery disease, smoking status and glomerular filtration rate were similar, GRACE and CRUSADE scores were higher in prior aspirin users (Figure 1). There was no significant difference between the two groups in terms of type and location of MI and reperfusion time.

Table 6 summarizes complications which occurred during hospitalization. Cardiogenic shock, stroke, in-hospital mortality and major bleeding were defined as a composite endpoint. In-hospital mortality and this composite endpoint were similar. Although GRACE and CRUSADE score were higher, prior aspirin users had lower infarct sizes as estimated by lower TnI peak. A significant correlation was found between TnI peak and GRACE score in all patients (Figure 2). 
Table 5 Baseline Characteristics of Study Patients According to Prior Aspirin Use

\begin{tabular}{|c|c|c|c|}
\hline & Prior Aspirin $(+)(n=2 \mid 2)$ & Prior Aspirin (-) $(n=350)$ & p-value \\
\hline Age, years & $68.7 \pm 8.6$ & $69.3 \pm 9.3$ & 0.497 \\
\hline Male sex, n (\%) & II4 (53.8) & $190(54.3)$ & 0.906 \\
\hline Body weight (kg) & $78.0 \pm 9.7$ & $77.3 \pm 9.4$ & 0.436 \\
\hline Height $(\mathrm{cm})$ & $167.3 \pm 6.9$ & $167.8 \pm 6.8$ & 0.444 \\
\hline Hypertension, n (\%) & $126(59.4)$ & $214(6 I . I)$ & 0.688 \\
\hline Diabetes mellitus, n (\%) & $60(28.3)$ & $98(28.0)$ & 0.938 \\
\hline Hyperlipidemia, n (\%) & $78(36.8)$ & $128(36.6)$ & 0.958 \\
\hline Smokers, n (\%) & $52(24.5)$ & $86(24.6)$ & 0.991 \\
\hline LVEF (\%) & $49.2 \pm 6.7$ & $48.9 \pm 8.2$ & 0.686 \\
\hline STEMI, n (\%) & $100(47.2)$ & $160(45.7)$ & 0.737 \\
\hline Culprit vessel (LAD), n (\%) & $74(34.9)$ & $122(34.9)$ & 0.991 \\
\hline Time to reperfusion (hours) & $4.2 \pm 2.4$ & $4.1 \pm 2.1$ & 0.567 \\
\hline GRACE score & $124.2 \pm 18.8$ & $120.2 \pm 19.8$ & 0.007 \\
\hline CRUSADE score & $30.4 \pm 10.7$ & $28.6 \pm 11.9$ & 0.082 \\
\hline \multicolumn{4}{|l|}{ Laboratory values at hospital admission } \\
\hline WBC $\left(\times 10^{3} / I\right)$ & $8.0 \pm 1.9$ & $8.6 \pm 2.1$ & 0.002 \\
\hline Hemoglobin (gr/dl) & $13.2 \pm 1.6$ & $13.4 \pm 1.5$ & 0.367 \\
\hline Platelet $\left(\times 10^{3} / \mathrm{I}\right)$ & $242.6 \pm 60.4$ & $247.4 \pm 59.3$ & 0.188 \\
\hline Blood glucose (mg/dl) & $114.2 \pm 47.7$ & $1 \mathrm{I} 4.4 \pm 43.7$ & 0.699 \\
\hline Serum creatinine $(\mathrm{mg} / \mathrm{dl})$ & $0.9 \pm 0.1$ & $0.9 \pm 0.2$ & 0.480 \\
\hline Troponin I (ng/mL) & $0.82(0.07-7.40)$ & $0.94(0.14-8.92)$ & 0.420 \\
\hline Total cholesterol (mg/dl) & $207.0 \pm 34.6$ & $204.1 \pm 42.7$ & 0.150 \\
\hline $\mathrm{LDL}(\mathrm{mg} / \mathrm{dl})$ & $\mid 29.1 \pm 29.9$ & $125.0 \pm 33.0$ & 0.130 \\
\hline $\mathrm{HDL}(\mathrm{mg} / \mathrm{dl})$ & $44.2 \pm 6.6$ & $42.9 \pm 9.3$ & 0.002 \\
\hline Triglycerides (mg/dl) & $166.0 \pm 66.0$ & $166.8 \pm 76.7$ & 0.518 \\
\hline \multicolumn{4}{|l|}{ Medication before AMI } \\
\hline ACE inhibitors/ARB, $n$ (\%) & $88(4 I .5)$ & $142(40.6)$ & 0.826 \\
\hline Beta-blockers, n (\%) & $12(5.7)$ & $6.3(6.3)$ & 0.763 \\
\hline Statins, n (\%) & $50(23.6)$ & $78(22.3)$ & 0.722 \\
\hline \multicolumn{4}{|l|}{ In-hospital antiplatelet use } \\
\hline Clopidogrel, n (\%) & $176(83.0)$ & $294(84.0)$ & 0.761 \\
\hline Ticagrelor, n (\%) & $24(11.3)$ & $40(11.4)$ & 0.969 \\
\hline Prasugrel, n (\%) & $12(5.7)$ & $18(5.1)$ & 0.791 \\
\hline Glycoprotein IIB/IIIA inhibitor, n (\%) & $20(9.4)$ & $28(8.0)$ & 0.556 \\
\hline \multicolumn{4}{|l|}{ In-hospital procedures } \\
\hline $\mathrm{PCl}, \mathrm{n}(\%)$ & $188(88.7)$ & $302(86.3)$ & $0.4 \mathrm{II}$ \\
\hline CABG, n (\%) & $16(7.5)$ & $32(9.1)$ & 0.512 \\
\hline Medically managed (\%) & $8(4.7)$ & $16(4.6)$ & 0.912 \\
\hline \multicolumn{4}{|l|}{ TIMI flow before $\mathrm{PCl}, \mathrm{n}$ (\%) } \\
\hline 0 & $72(33.9)$ & $124(35.4)$ & 0.724 \\
\hline 1 & $14(6.6)$ & $14(6.6)$ & 0.467 \\
\hline \multicolumn{4}{|l|}{ TIMI flow after PCI, n (\%) } \\
\hline $0-1$ & $3(1.4)$ & $5(1.4)$ & 0.990 \\
\hline II-III & $209(98.6)$ & $345(98.6)$ & 0.990 \\
\hline
\end{tabular}

Note: Data is presented as mean \pm SD or $\mathrm{n}(\%)$.

Abbreviations: ACE, angiotensin-converting enzyme; AMI, acute myocardial infarction; APT, antiplatelet therapy; ARB, angiotensin II receptor blocker; CABG, coronary artery bypass graft; CRUSADE, Can Rapid risk stratification of Unstable angina patients Suppress ADverse outcomes with Early implementation of the ACC/AHA guidelines; DAPT, dual antiplatelet therapy; eGFR, estimated glomerular filtration rate; GRACE, Global Registry of Acute Coronary Events; HDL, high density lipoprotein; hs-CRP, high-sensitivity C-reactive protein; LAD, left anterior descending coronary artery; LDL, low density lipoprotein; LVEF, left ventricular ejection fraction; MI, myocardial infarction; PCl, percutaneous coronary intervention; SAPT, single antiplatelet therapy; STEMI, ST-segment elevation myocardial infarction; TIMI, Thrombolysis in Myocardial Infarction; WBC, white blood cell. 


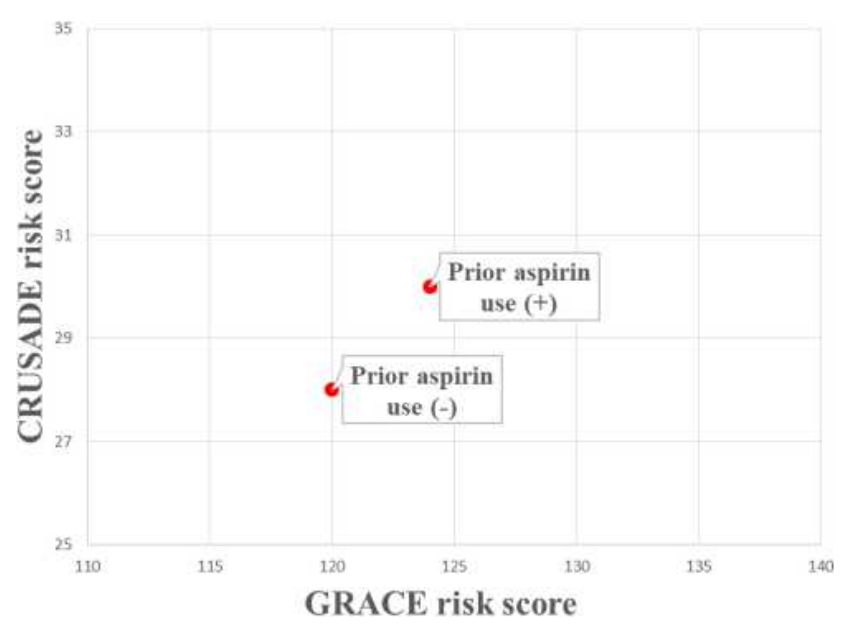

Figure I Comparison of GRACE and CRUSADE scores in patients with and without antecedent aspirin use. GRACE: Mean Global Registry of Acute Coronary Events; CRUSADE: Can Rapid risk stratification of Unstable angina patients Suppress ADverse outcomes with Early implementation of the ACC/ AHA guidelines.

Statistical stability of prior aspirin use to reduce infarct size was maintained after integration of GRACE score, MI location (anterior vs non-anterior),
MI type (STEMI vs NSTEMI), prior beta blocker and statin use and smoking status in the multiple linear regression analysis (Table 7). This finding has been consistently verified in both STEMI and NSTEMI subgroups (Tables 1 and 2).

CRUSADE score (OR 1.131, 95\% CI 1.097-1.167; $\mathrm{p}<0.001$ ), clopidogrel treatment (OR 2.691, 95\% CI 1.334-5.429; $\mathrm{p}=0.038$ ) and glycoprotein IIB/IIIA inhibitors (OR 4.462, 95\% CI 1.815-10.973; $\mathrm{p}=$ 0.001 ) were found to be significant independent predictors of bleeding in multivariate analysis (Table 8). However, prior aspirin use was not associated with bleeding in either STEMI or NSTEMI subgroups (Tables 3 and 4).

Despite major bleeding and minor bleeding being similar in the two groups, minimal bleeding was higher in prior aspirin users (Table 6). When minimal bleeding was adjusted for CRUSADE score in the multiple logistic regression analysis, the difference between the two groups in terms of minimal bleeding disappeared (Figure 3).

Table 6 In-Hospital Adverse Events and Troponin I Peak Value of Study Patients According to Antecedent Aspirin Use

\begin{tabular}{|c|c|c|c|}
\hline & Prior ASA (+) $(n=2 \mid 2)$ & Prior ASA (-) $(n=350)$ & p-value \\
\hline Death, n (\%) & $4(1.9)$ & $6(1.7)$ & $0.88 I$ \\
\hline Cardiogenic shock, n (\%) & $10(4.7)$ & $8(2.3)$ & 0.113 \\
\hline APE, n (\%) & $14(6.6)$ & $16(4.6)$ & 0.299 \\
\hline MV, n (\%) & $8(3.8)$ & $10(2.9)$ & 0.550 \\
\hline Atrial fibrillation, $n$ (\%) & $16(7.5)$ & $26(7.4)$ & 0.959 \\
\hline AV block, n (\%) & $6(2.8)$ & $10(2.9)$ & 0.985 \\
\hline VT/VF, n (\%) & $16(7.5)$ & $20(5.7)$ & 0.390 \\
\hline Minimal bleeding, n (\%) & $24(11.3)$ & $22(6.3)$ & 0.039 \\
\hline Minor bleeding, n (\%) & $7(3.3)$ & $12(3.4)$ & 0.696 \\
\hline Major bleeding, n (\%) & $4(1.9)$ & $6(1.7)$ & $0.88 \mathrm{I}$ \\
\hline AKI requiring hemodialysis, $n(\%)$ & $18(8.5)$ & $34(9.7)$ & 0.627 \\
\hline Hemorrhagic stroke, n (\%) & $0(0)$ & $0(0)$ & 1.000 \\
\hline Ischemic stroke, n (\%) & $2(0.9)$ & $4(1.1)$ & 0.824 \\
\hline Composite endpoint, n (\%) & $19(9.0)$ & $20(5.7)$ & 0.142 \\
\hline Troponin I peak value $(\mathrm{ng} / \mathrm{mL})$ & II.0 (4.5-3|.9) & $14.7(6.7-42.9)$ & 0.002 \\
\hline
\end{tabular}

Note: Data is presented as median \pm interquartile range (IQR) or $n(\%)$.

Abbreviations: AKI, acute kidney injury; APE, acute pulmonary edema; APT, antiplatelet therapy; AV, atrioventricular; DAPT, dual antiplatelet therapy; MV, mechanical ventilation; VT/VF, ventricular tachycardia/ventricular fibrillation; Composite endpoint, composite of in-hospital mortality, stroke, cardiogenic shock and major bleeding. 


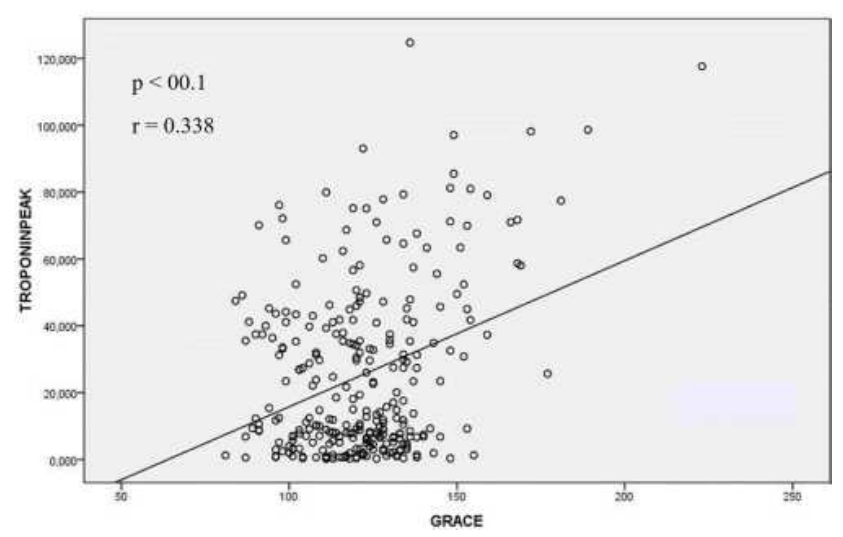

Figure 2 The close relation between Troponin I peak value and GRACE score in all patients. GRACE: Mean Global Registry of Acute Coronary Events.

\section{Discussion}

The main findings of the present study were as follows. (1) Although patients with prior aspirin use had a higher GRACE score, smaller infarct size, which was determined by TnI peak value, was reported. (2) There was no difference between those who used aspirin and those who did not in terms of occurrence of major and minor bleeding. Minimal bleeding was more frequently seen in antecedent aspirin users. However, when minimal bleeding was integrated into regression analysis with CRUSADE score, a similar odds ratio was reported. (3) A composite endpoint including in-hospital mortality, cardiogenic shock, stroke and major bleeding was similar between the two groups.
The clinical utility of aspirin, particularly in MI, has always been attributed to its antiplatelet effect. Recent studies have shown that it might reduce infarct size by cardioprotective mechanisms. ${ }^{29,30}$ It is still unclear whether antecedent aspirin use is beneficial or harmful.

Chronic aspirin users had a worse baseline cardiovascular risk profile than those who did not. GRACE score, in particular, was higher in those using aspirin. Despite the higher basal ischemic risk, chronic aspirin users had a lower TnI peak in our study. In concordance with this study, Campodonico et al found smaller infarct size in chronic MI patients receiving antiplatelet treatment. ${ }^{31}$ It is noteworthy to emphasize that patients were assigned to one of three groups based on the number of antiplatelet agents used (no, single and dual antiplatelet groups) in their study. Weidmann et al concluded that pre-existing treatment with aspirin and/or statins, particularly in combination, decreased infarct size. ${ }^{30}$ Additionally, Marenzi et al reported that sole statin pretreatment was associated with smaller infarct size in STEMI. ${ }^{32}$ The net effect of aspirin was found to be significantly higher than statin pretreatment for infarct size in our study. However, only $20 \%$ of the total study population was using antecedent statin therapy and this study was not designed to determine the net effect of statin pretreatment.

Chronic aspirin use was shown to be associated with increased major bleeding in primary prevention. ${ }^{8}$ Additionally the use of low dose aspirin in older adults

Table 7 Multiple Linear Regression Analysis for Infarct Size

\begin{tabular}{|c|c|c|c|c|}
\hline & \multicolumn{4}{|l|}{ Infarct Size } \\
\hline & $\begin{array}{l}\text { BETA (Non-standard } \\
\text { Coefficient) }\end{array}$ & $\begin{array}{l}95 \% \mathrm{Cl} \text { for } \\
\text { BETA }\end{array}$ & $\begin{array}{l}\text { BETA (Standard } \\
\text { Coefficient) }\end{array}$ & p-value \\
\hline Prior aspirin treatment & 8.346 & $6.207-10.485$ & 0.160 & $<0.001$ \\
\hline GRACE score & 0.214 & $0.156-0.271$ & 0.165 & $<0.001$ \\
\hline $\begin{array}{l}\text { AMI location (anterior vs } \\
\text { nonanterior) }\end{array}$ & 10.889 & $8.605-13.174$ & 0.205 & $<0.001$ \\
\hline AMI type (STEMI vs NSTEMI) & 36.393 & $34.213-38.572$ & 0.718 & $<0.001$ \\
\hline Smoking status & 6.976 & $4.50 I-9.45 I$ & 0.119 & $<0.001$ \\
\hline Prior beta-blocker treatment & 0.740 & $-3.610-5.089$ & 0.007 & 0.738 \\
\hline Prior statin treatment & 0.626 & $-1.869-3.120$ & 0.010 & 0.622 \\
\hline
\end{tabular}

Abbreviations: AMI, acute myocardial infarction; GRACE, Global Registry of Acute Coronary Events; NSTEMI, non-ST-elevation myocardial infarction; STEMI, ST-elevation myocardial infarction. 
Table 8 Univariate and Multivariate Logistic Regression Analysis for Bleeding

\begin{tabular}{|c|c|c|c|c|}
\hline \multirow[t]{2}{*}{ Variables } & \multicolumn{2}{|l|}{ Univariate Analysis } & \multicolumn{2}{|l|}{ Multivariate Analysis } \\
\hline & Odds Ratio (95\% Cl) & p-value & Odds Ratio (95\% Cl) & p-value \\
\hline Prior aspirin treatment & I.I76 (0.70I-I.970) & 0.531 & & \\
\hline Age & 1.001 (0.973-I.029) & 0.959 & & \\
\hline Hypertension & $1.954(1.108-3.447)$ & 0.021 & $0.940(0.492-1.798)$ & 0.852 \\
\hline CRUSADE score & $1.129(1.096-1.162)$ & $<0.001$ & I.I3I (1.097-I.I67) & $<0.001$ \\
\hline Clopidogrel treatment & $2.038(1.127-3.687)$ & 0.018 & 2.691 (1.334-5.429) & 0.038 \\
\hline Ticagrelor treatment & $2.302(1.194-4.439)$ & 0.013 & $0.624(0.153-2.543)$ & 0.510 \\
\hline Glycoprotein IIB/IIIA inhibitor treatment & $2.726(1.34 I-5.544)$ & 0.006 & $4.462(1.815-10.973)$ & 0.001 \\
\hline
\end{tabular}

Abbreviation: CRUSADE, Can Rapid risk stratification of Unstable angina patients Suppress ADverse outcomes with Early implementation of the American College of Cardiology/American Heart Association guidelines.

(> 70 years) resulted in major hemorrhage. ${ }^{33}$ Gastrointestinal bleeding accounts for up to half of major bleeding. ${ }^{6}$ The absolute benefits of aspirin pretreatment were largely counterbalanced by the bleeding hazard. We also investigated the relationship between chronic aspirin use and in-hospital bleeding. Contrary to expectations, there was no difference in the occurrence of major and minor bleeding events between those using aspirin and those who did not. Minimal bleeding was more frequent in prior aspirin users. However, when the risk of bleeding due to aspirin was adjusted according to the CRUSADE score, there was no significant bleeding in terms of minimal bleeding. While most previous studies investigating the role of antecedent aspirin therapy were large retrospective analyses with limited inclusion criteria, our study was established to specifically prospectively

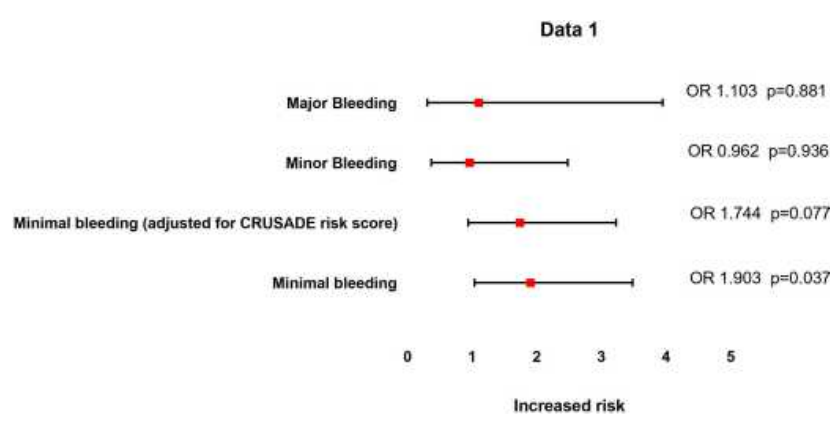

Figure 3 Comparison of bleeding in patients with and without antecedent aspirin use. Patients without prior aspirin use were accepted as the reference point. Minimal bleeding and CRUSADE score were integrated in multiple regression analysis. CRUSADE: Can Rapid risk stratification of Unstable angina patients Suppress ADverse outcomes with Early implementation of the ACC/AHA guidelines. evaluate consecutive de novo AMI patients using inclusion criteria in accordance with current practice. ${ }^{34-37}$ The strength of our study is evaluating bleeding complications using standardized bleeding classifications. ${ }^{26}$

Time from presentation to intervention has a substantial impact on infarct size. Primary PCI is the treatment of choice in STEMI within 12 hours of symptom onset. ${ }^{24}$ Time from presentation to intervention was approximately 4 hours in this study. It included 2 hours European Society of Cardiology-mandated door to balloon time. ${ }^{24}$ It was an acceptable duration for a 7/24 PCI-capable hospital. An early invasive strategy is defined as coronary angiography performed within 24 hours of hospital admission in NSTEMI, ${ }^{4}$ which is recommended in high-risk patients. ${ }^{4}$ All patients were taken to the angiography laboratory as soon as possible in this study. However, it cannot be denied that 4 hours is not achievable in ordinary conditions for NSTEMI. All patients received an aspirin $300 \mathrm{mg}$ loading dose on arrival at hospital, irrespective of prior aspirin use. Inhibition of the cyclooxygenase and attenuation of thromboxane A2 were achieved within minutes with a loading dose of 250-500 $\mathrm{mg}$. The rapid action of aspirin might decrease infarct size.

Cardiovascular magnetic resonance (CMR) imaging allows noninvasive assessment of myocardial function and viability with high spatial resolution and is superior to single-photon emission computed tomography (SPECT) for the identification of MI. ${ }^{38,39}$ Furthermore, the technique is highly sensitive and permits quantification of small areas of myocardial injury attributable to native coronary artery disease and/or PCI. ${ }^{40,41}$ It was considered to be the most 
reliable indicator of infarct size. Tn was also shown to be closely related to infarct size after STEMI. ${ }^{42}$ Peak values, in particular, correlated well with infarct size. ${ }^{43}$ Low cost and high availability favor TnI instead of imaging modalities for identifying infarct size in current practice.

Some limitations should be taken into consideration while interpreting our data. First, confounding factors including creatinine clearance and slow or incomplete reperfusion could not be totally eliminated while showing the direct relationship between antecedent aspirin use and infarct size. Second, patients' self-reported prior aspirin use was subjective. Third, many factors, including access site and anticoagulants, might cause serious bleeding rather than those identified by CRUSADE score. Finally, large prospective trials should be conducted to find associations between prior aspirin use and long-term mortality in acute MI.

\section{Conclusions}

Patients who were hospitalized with de novo MI and were chronic aspirin users had an unexpectedly lower TnI peak level and similar bleeding compared to those who did not use aspirin, despite having a higher initial ischemic and bleeding risk profile. These findings may shed light on the contemporary preventive role of aspirin in acute MI.

\section{Ethical Approval}

All procedures performed in studies involving human participants were in accordance with the ethical standards of the institutional and/or national research committee and with the 1964 Declaration of Helsinki and its later amendments or comparable ethical standards.

\section{Funding}

This research did not receive any specific grant from funding agencies in the public, commercial, or not-forprofit sectors.

\section{Disclosure}

The authors declare that they have no conflicts of interest. The authors alone are responsible for the content and writing of the paper. The authors have had full control of all primary data and they agree to allow the journal to review their data if requested.

\section{References}

1. Antithrombotic Trialists' (ATT) Collaboration, Baigent C, Blackwell L, Collins R, et al. Aspirin in the primary and secondary prevention of vascular disease: collaborative meta-analysis of individual participant data from randomised trials. Lancet. 2009;373 (9678):1849-1860.

2. Spencer FA, Santopinto JJ, Gore JM, et al. Impact of aspirin on presentation and hospital outcomes in patients with acute coronary syndromes (The Global Registry of Acute Coronary Events [GRACE]). Am J Cardiol. 2002;90:1056-1061. doi:10.1016/S00029149(02)02769-8

3. Fras Z, Sahebkar A, Banach M. The use of aspirin in contemporary primary prevention of atherosclerotic cardiovascular diseases revisited: the increasing need and call for a personalized therapeutic approach. Am J Cardiovasc Drugs. 2021;21:139-151. doi:10.1007/ s40256-020-00424-y

4. Collet JP, Thiele H, Barbato E, et al. 2020 ESC Guidelines for the management of acute coronary syndromes in patients presenting without persistent ST-segment elevation: the Task Force for the management of acute coronary syndromes in patients presenting without persistent ST-segment elevation of the European Society of Cardiology (ESC). Eur Heart J. 2020;42(14):1289-1367.

5. Degano IR, Salomaa V, Veronesi G, et al. Twenty-five-year trends in myocardial infarction attack and mortality rates, and case-fatality, in six European populations. Heart. 2015;101:1413-1421. doi:10.1136/ heartjnl-2014-307310

6. ASCEND Study Collaborative Group, Bowman L, Mafham M, Wallendszus K, et al. Effects of aspirin for primary prevention in persons with diabetes mellitus. $N$ Engl $J$ Med. 2018;379 (16):1529-1539.

7. Gaziano JM, Brotons C, Coppolecchia R, et al. Use of aspirin to reduce risk of initial vascular events in patients at moderate risk of cardiovascular disease (ARRIVE): a randomised, double-blind, placebo-controlled trial. Lancet. 2018;392(10152):1036-1046. doi:10.1016/S0140-6736(18)31924-X

8. Whitlock EP, Burda BU, Williams SB, et al. Bleeding risks with aspirin use for primary prevention in adults: a systematic review for the U.S. Preventive Services Task Force. Ann Intern Med. 2016;164 (12):826-835. doi:10.7326/M15-2112

9. Brener SJ, Mehran R, Lansky AJ, et al. Pretreatment with aspirin in acute coronary syndromes: lessons from the ACUITY and HORIZONS-AMI trials. Eur Heart $J$ Acute Cardiovasc Care. 2016;5(5):449-454. doi:10.1177/2048872615624848

10. Arnett DK, Blumenthal RS, Albert MA, et al. 2019 ACC/AHA guideline on the primary prevention of cardiovascular disease: a report of the American College of Cardiology/American Heart Association Task Force on Clinical Practice Guidelines. Circulation. 2019;140(11):e596-e646. doi:10.1161/CIR.0000000000000678

11. Wagdy HM, Christian TF. Determinants of infarct size in acute myocardial infarction in patients treated with reperfusion therapy. Curr Opin Cardiol. 1996;11(4):369-377. doi:10.1097/00001573199607000-00005

12. Arruda-Olson AM, Roger VL, Jaffe AS, et al. Troponin T levels and infarct size by SPECT myocardial perfusion imaging. JACC Cardiovasc Imaging. 2011;4(5):523-533. doi:10.1016/j. jcmg.2011.03.010

13. Omura T, Teragaki M, Tani T, et al. Estimation of infarct size using serum troponin $\mathrm{T}$ concentration in patients with acute myocardial infarction. Jpn Circ J. 1993;57:1062-1070. doi:10.1253/jcj.57.1062

14. Chia S, Senatore F, Raffel OC, et al. Utility of cardiac biomarkers in predicting infarct size, left ventricular function, and clinical outcome after primary percutaneous coronary intervention for ST segment elevation myocardial infarction. JACC Cardiovasc Interv. 2008;1:415-423. doi:10.1016/j.jcin.2008.04.010 
15. Giannitsis E, Steen H, Kurz K, et al. Cardiac magnetic resonance imaging study for quantification of infarct size comparing directly serial versus single time-point measurements of cardiac troponin $\mathrm{T}$. J Am Coll Cardiol. 2008;51:307-314. doi:10.1016/j.jacc.2007.09.041

16. Kappagoda T, Amsterdam E. Aspirin for primary prevention of myocardial infarction: what is the evidence? J Cardiopulm Rehabil Prev. 2012;32(1):1-8. doi:10.1097/HCR.0b013e31822flaa7

17. Wu E, Ortiz JT, Tejedor P, et al. Infarct size by contrast enhanced cardiac magnetic resonance is a stronger predictor of outcomes than left ventricular ejection fraction or end-systolic volume index: prospective cohort study. Heart. 2008;94:730-736. doi:10.1136/ hrt.2007.122622

18. Fox KAA, Dabbous OH, Goldberg RJ, et al. Prediction of risk of death and myocardial infarction in the six months after presentation with acute coronary syndrome: prospective multinational observational study (GRACE). BMJ. 2006;333(7578):1091. doi:10.1136/ bmj.38985.646481.55

19. Subherwal S, Bach RG, Chen AY, et al. Baseline risk of major bleeding in non-ST-segment-elevation myocardial infarction: the CRUSADE (Can Rapid risk stratification of Unstable angina patients Suppress ADverse outcomes with Early implementation of the ACC/ AHA Guidelines) bleeding score. Circulation. 2009;119(14):18731882. doi:10.1161/CIRCULATIONAHA.108.828541

20. McConnachie A, Walker A, Robertson M, et al. Long-term impact on healthcare resource utilization of statin treatment, and its cost effectiveness in the primary prevention of cardiovascular disease: a record linkage study. Eur Heart J. 2014;35:290-298. doi:10.1093/eurheartj/ eht232

21. Mistry H, Morris S, Dyer M, et al. Cost-effectiveness of a European preventive cardiology programme in primary care: a Markov modelling approach. BMJ Open. 2012;2:e01029. doi:10.1136/bmjopen2012-001029

22. Pereira M, Azevedo A, Lunet N, et al. Explaining the decline in coronary heart disease mortality in Portugal between 1995 and 2008. Circ Cardiovasc Qual Outcomes. 2013;6:634-642. doi:10.1161/ CIRCOUTCOMES.113.000264

23. Piepoli MF, Hoes AW, Agewall S, et al. 2016 European Guidelines on cardiovascular disease prevention in clinical practice: the Sixth Joint Task Force of the European Society of Cardiology and Other Societies on Cardiovascular Disease Prevention in Clinical Practice (constituted by representatives of 10 societies and by invited experts) Developed with the special contribution of the European Association for Cardiovascular Prevention \& Rehabilitation (EACPR). Eur Heart J. 2016;37(29):2315-2381. doi:10.1093/eurheartj/ehw106

24. Ibanez B, James S, Agewall S, et al. 2017 ESC Guidelines for the management of acute myocardial infarction in patients presenting with ST-segment elevation: the Task Force for the management of acute myocardial infarction in patients presenting with ST-segment elevation of the European Society of Cardiology (ESC). Eur Heart J. 2018;39(2):119-177. doi:10.1093/eurheartj/ehx393

25. Thygesen K, Alpert JS, Jaffe AS, et al. Fourth universal definition of myocardial infarction. Eur Heart J. 2018;40(3):237-269. doi:10.1093/eurheartj/ehy462

26. Chesebro JH, Knatterud G, Roberts R, et al. Thrombolysis in Myocardial Infarction (TIMI) Trial, Phase I. A comparison between intravenous tissue plasminogen activator and intravenous streptokinase. Clinical findings through hospital discharge. Circulation. 1987;76:142-154. doi:10.1161/01.CIR.76.1.142

27. De Carlo M, Borelli G, Gistri R, et al. Effectiveness of the transradial approach to reduce bleedings in patients undergoing urgent coronary angioplasty with GPIIb/IIIa inhibitors for acute coronary syndromes. Catheter Cardiovasc Interv. 2009;74(3):408-415. doi:10.1002/ ccd. 22008

28. TIMI Study Group. The thrombolysis in myocardial infarction (TIMI) trial. Phase I Findings N Engl J Med. 1985;312:932-936. doi:10.1056/NEJM198504043121437
29. Schrottmaier WC, Kral JB, Badrnya S, et al. Aspirin and P2Y12 Inhibitors in platelet-mediated activation of neutrophils and monocytes. Thromb Haemost. 2015;114(3):478-489. doi:10.1160/ TH14-11-0943

30. Weidmann L, Oeid S, Mach F, et al. Pre-existing treatment with aspirin or statins influences clinical presentation, infarct size and inflammation in patients with de novo acute coronary syndromes. Int J Cardiol. 2019;275:171-178. doi:10.1016/j.ijcard.2018.10.050

31. Campodonico J, Cosentino N, Milazzo V, et al. Impact of chronic antiplatelet therapy on infarct size and bleeding in patients with acute myocardial infarction. Cardiovasc Pharmacol Ther. 2018;23 (5):407-413. doi:10.1177/1074248418769636

32. Marenzi G, Cosentino N, Cortinovis S, et al. Myocardial infarct size in patients on long-term statin therapy undergoing primary percutaneous coronary intervention for ST-elevation myocardial infarction. Am J Cardiol. 2015;116(12):1791-1797. doi:10.1016/j.amjcard.2015.09.016

33. McNeil JJ, Wolfe R, Woods RL, et al. Effect of aspirin on cardiovascular events and bleeding in the healthy elderly (ASPREE). $N$ Engl J Med. 2018;379(16):1509-1518. doi:10.1056/ NEJMoa1805819

34. Ambrosio G, Steinhubl S, Gresele P, et al. Impact of chronic antiplatelet therapy before hospitalization on ischemic and bleeding events in invasively managed patients with acute coronary syndromes: the ACUITY trial. Eur J Cardiovasc Prev Rehabil. 2011;18(1):121-128. doi:10.1097/HJR.0b013e32833bc070

35. Alexander JH, Harrington RA, Tuttle RH, et al. Prior aspirin use predicts worse outcomes in patients with non-ST-elevation acute coronary syndromes. PURSUIT Investigators. Platelet IIb/IIIa in Unstable angina: receptor Suppression Using Integrilin Therapy. Am $J$ Cardiol. 1999;83(8):1147-1151. doi:10.1016/S0002-9149(99) 00049-1

36. Rich JD, Cannon CP, Murphy SA, et al. Prior aspirin use and outcomes in acute coronary syndromes. $J$ Am Coll Cardiol. 2010;56 (17):1376-1385. doi:10.1016/j.jacc.2010.06.028

37. Portnay EL, Foody JM, Rathore SS, et al. Prior aspirin use and outcomes in elderly patients hospitalized with acute myocardial infarction. J Am Coll Cardiol. 2005;46(6):967-974. doi:10.1016/j. jacc.2005.06.049

38. Kim RJ, Fieno DS, Parrish TB, et al. Relationship of MRI delayed contrast enhancement to irreversible injury, infarct age, and contractile function. Circulation. 1999;100:1992-2002. doi:10.1161/01. CIR.100.19.1992

39. Wagner A, Mahrholdt H, Holly TA, et al. Contrast-enhanced MRI and routine single photon emission computed tomography (SPECT) perfusion imaging for detection of subendocardial myocardial infarcts: an imaging study. Lancet. 2003;361:374-379. doi:10.1016/ S0140-6736(03)12389-6

40. Ricciardi MJ, Wu E, Davidson CJ, et al. Visualization of discrete microinfarction after percutaneous coronary intervention associated with mild creatine kinase-MB elevation. Circulation. 2001;103:2780-2783. doi:10.1161/hc2301.092121

41. Selvanayagam JB, Porto I, Channon K, et al. Troponin elevation after percutaneous coronary intervention directly represents the extent of irreversible myocardial injury. Insights from cardiovascular magnetic resonance imaging. Circulation. 2005;111:1027-1032. doi:10.1161/ 01.CIR.0000156328.28485.AD

42. Mayr A, Mair J, Klug G, et al. Cardiac troponin T and creatine kinase predict midterm infarct size and left ventricular function after acute myocardial infarction: a cardiac MR study. J Magn Reson Imag JMRI. 2011;33:847-854. doi:10.1002/jmri.22491

43. Boden H, Ahmed TA, Velders MA, et al. Peak and fixed-time high-sensitive troponin for prediction of infarct size, impaired left ventricular function, and adverse outcomes in patients with first ST-segment elevation myocardial infarction receiving percutaneous coronary intervention. Am J Cardiol. 2013;111:1387-1393. doi:10.1016/j.amjcard.2013.01.284 


\section{Publish your work in this journal}

Therapeutics and Clinical Risk Management is an international, peerreviewed journal of clinical therapeutics and risk management, focusing on concise rapid reporting of clinical studies in all therapeutic areas, outcomes, safety, and programs for the effective, safe, and sustained use of medicines. This journal is indexed on PubMed Central, CAS,
EMBase, Scopus and the Elsevier Bibliographic databases. The manuscript management system is completely online and includes a very quick and fair peer-review system, which is all easy to use. Visit http://www.dovepress.com/testimonials.php to read real quotes from published authors. 